\title{
SINEMATIK TEROR: EKSEPSIONALISME AMERIKA DAN PROPAGANDA ANTI-ISLAM DALAM FILM 12 STRONG
}

\author{
Sekar Yolanda Azza \\ Universitas Muhammadiyah Lampung, Lampung, Indonesia \\ Email: sekaryolandaazza@gmail.com \\ Yusrina Dinar Prihatika \\ Universitas Gadjah Mada, Yogyakarta, Indonesia \\ Email: dinarprihatika@gmail.com
}

\begin{tabular}{c} 
Article history: \\
Submitted July 13, 2021 \\
Revised Sept 27, 2021 \\
Accepted Nov 23, 2021 \\
Published Dec 03, 2021 \\
\hline
\end{tabular}

\begin{abstract}
The concept of American exceptionalism in American cinema is a way for propagandists to instill certain values or doctrines in the audience. This is clearly depicted through the narrative and non-narrative aspects where each dialogue, characterization, setting and also the way the camera take a shot reflects an effort of exceptionalism that is implanted throughout the film. These efforts led to the practice of propaganda against Islam and Muslim. By using a descriptive analysis method described using binary opposition theory, this research reveals the existence of American exceptionalism indoctrination which has an impact on the emergence of anti-Islamic ideology. The existence of a propaganda technique that is reflected in the film, such as card stacking, creates a cinematic terror in the film about the depiction of Middle Eastern people, especially Muslims.
\end{abstract}

Keywords: American exceptionalism; propaganda; anti-Islam; islamophobia

\begin{abstract}
ABSTRAK
Konsep eksepsionalitas Amerika dalam karya sinema Amerika merupakan suatu jalan bagi para pelaku propaganda untuk menanamkan nilai-nilai tertentu atau doktrin kepada penonton. Hal ini ditunjukkan dengan jelas melalui sisi naratif dan non-naratif dimana setiap dialog, karakterisasi, setting dan juga pengambilan gambar mencerminkan adanya suatu upaya eksepsionalitas yang ditanamkan sepanjang film. Upaya tersebut berujung dengan praktik propaganda terhadap islam dan umat muslim. Dengan menggunakan metode analisis diskriptif yang dijabarkan menggunakan teori oposisi biner, penelitian ini mengungkap adanya indoktrinasi eksepsionalisme Amerika yang berimbas pada munculnya paham antiIslam. Adanya salah satu teknik propaganda yang tercermin di dalam film seperti card stacking yang memunculkan adanya sinematik terror dalam film tentang penggambaran orang Timur Tengah terutama orang muslim.
\end{abstract}


Kata Kunci : eksepsionalitas Amerika; propaganda; anti-Islam; islamophobia

\section{PENDAHULUAN}

Sebagai bagian dari sastra, film memiliki tempat yang strategis guna mencerminkan, memberikan kritik, dan tidak jarang melakukan propaganda. Film 12 Strong (Hemsworth, et al. 2018) menghadirkan nuansa pelik daerah Afghanistan yang pada saat itu sedang dikuasi oleh kelompok Taliban. Film ini dimulai dengan adegan terorisme di gedung 2 World Trade Center pada februari 1993 dan dilanjut dengan aksi terorisme di gedung duta besar Amerika Serikat di Nairobi dan Der es Salaam, Afrika pada Agustus 1998. Film 12 Strong juga mengingatkan penonton dengan aksi terorisme yang terjadi pada kapal angkatan laut Amerika Serikat pada tahun 2000. Tidak hanya itu, film ini menyinggung jaringan terorisme yang kembali menyerang World Trade Center pada 11 September 2001 dan dalang dari semua aksi ini adalah jaringan terorisme Bin Laden atau Taliban.

Satu hari setelah kejadian terorisme 9/11, Kapten Mitch Nelson yang diperankan oleh Chris Hemsworth mengajukan diri untuk memimpin pasukannya yang berjumlah sebelas orang untuk menjalankan misi pembalasan dendam Amerika Serikat pada kelompok Al-Qaeda dengan menghancurkan kelompok pertahanan Taliban di Afghanistan. Sesampainya di Uzbekistan, pasukan khusus yang dipimpin Nelson diperintahkan bertemu dengan agen C.I.A untuk kemudian dipertemukan dengan Aliansi Utara bernama Jendral Abdul Rashid Dostum. Menjalin kerjasama dengan pasukan Dostum tidaklah mudah, pasukan Nelson harus bisa mendapatkan kepercayaan Dostum untuk memulai misi mereka di Afghanistan.

Kapten Nelson dan pasukannya diberikan waktu enam minggu untuk menyelesaikan misi ini namun Nelson mengatakan hanya memerlukan waktu selama tiga minggu. Sesampainya di Alamo atau markas pasukan Jendral Abdul Dostum mereka mendiskusikan misi untuk menghancurkan markas Taliban. Misi mulai berjalan sesuai rencana hingga salah satu rekan Nelson 
mengatakan bahwa akan ada satu pasukan lagi yang dikirim Amerika untuk melancarkan misi ini. Pasukan tersebut bekerjasama dengan Jendral Atta Mohammed yang merupakan musuh dari Jendral Dostum. Karena hal ini, Dostum memilih untuk melepaskan Kapten Nelson dan pasukan Amerika.

Pasukan Amerika Serikat berhasil menyerang markas pertahanan Taliban namun mereka mengalami kekalahan karena jumlah pasukan yang lebih sedikit dibanding jumlah pasukan Taliban. Sebelum pasukan Nelson mengalami kekalahan, bantuan pasukan yang dipimpin Jendral Dostum datang sehingga markas Taliban berhasil dikuasai oleh pasukan Nelson dan Dostum. Kemenangan ini membuat jendral Dostum mendapatkan kembali daerah Mazar-I-Sharif yang sebelumnya dikuasai oleh Taliban. Setelah berhasil menyelesaikan misi dengan baik, Kapten Nelson dan pasukannya kembali ke Amerika Serikat dan meninggalkan Afghanistan.

Film 12 Strong menarik untuk diteliti sebab kisahnya merupakan kisah nyata pasukan militer khusus ODA 595. Meskipun kejadian 9/11 sudah cukup lama terjadi namun dampak yang dirasakan oleh kelompok Muslim Amerika masih terus berlanjut. Hal ini ditunjukan dengan 62\% Muslim Amerika yang mengalami diskriminasi pada tahun 2019 (Institute for Social Policy and Understanding 2019). Selain berdampak pada diskriminasi Muslim, 9/11 juga kembali menghidupkan semangat eksepsionalisme yang sudah pudar sejak berakhirnya perang dingin tahun 1991. Hal ini tergambar saat Presiden Amerika pada masa itu, George W. Bush dengan pidatonya “Amerika menjadi sasaran serangan karena kami adalah mercusuar paling terang untuk kebebasan di dunia. Dan tidak ada yang bisa mencegah cahaya itu bersinar" (Janz 2010). Melalui ucapan Bush, eksepsionalisme Amerika menjadi semangat awal masyarakat Amerika Serikat sebagai serangan balasan bagi kelompok radikal muslim.

Eksepsionalisme Amerika adalah ideologi yang meyakini bahwa Amerika adalah bangsa pilihan Tuhan yang memiliki misi untuk menyebarkan nilai serta kekuatan untuk melawan kejahatan (Barnett 2016). Menyadari 
kemampuan film dalam menyebarkan ideologi dan melakukan propaganda, Woodrow Wilson melalui Committee on Public Information (CPI) pada tahun 1917 pernah meminta Hollywood untuk memproduksi dan mendukung kebijakan Amerika dalam menghadapi Perang Dunia I (McFadden 2012). Hingga saat ini industri Hollywood masih memiliki andil dalam menyebarkan propaganda secara modern termasuk propaganda anti-muslim. Dalam penelitiannya, (Diaz, 2017) mengatakan bahwa representasi Islam atau Timur Tengah sebagai terorisme dalam film Hollywood tak luput dari adanya hiperrealisme sinematik paska 9/11, representasi diwujudkan dalam hal sinematik juga sonifikasi. Hal ini membuat pemikiran negatif terhadap Muslim, Islam, dan Timur Tengah.

Masih maraknya diskriminasi yang dialami oleh muslim Amerika membuat penelitian ini perlu dilakukan. Penelitian ini berfokus untuk menjawab permasalahan bagaimana gambaran eksepsionalisme Amerika dan bagaimana kaitannya dengan bentuk propaganda anti-Muslim dalam film 12 Strong. Penelitian ini penting dilakukan guna memberikan perspektif lain atas stereotipe kelompok Muslim khususnya Muslim Amerika. Penelitian ini juga diharap dapat membuat penonton dan penikmat film lebih peka akan adanya propaganda anti-Muslim dalam film yang ditonton. Industri Hollywood juga diharap dapat berhati-hati dalam menggambarkan fenomena melalui narasi maupun gambar agar stereotipe dan diskriminasi tidak menimpa suatu kelompok apapun.

Berbagai kajian disiplin ilmu selalu mengembangkan wawasan tentang propaganda anti-Muslim melalui kajian penelitian. Studi terkait telah dilakukan oleh Mohd Nazri Latiff Azmi, Mohd Nawaf Ab, et al dengan judul "An Analysis of Stereotype and Agenda Setting Theories in the Portrayal of Muslims in The Kingdom" (Azmi, et al. 2016). Hasil studi menunjukkan bahwa film The Kingdom menggambarkan Muslim sebagai teroris dan mempengaruhi citra Muslim dan Islam secara negatif. Teori Pengaturan Agenda atau Agenda Setting Theory digunakan dalam studi ini. 
Studi terkait berikutnya dilakukan oleh Mas Ian Rif'ati, Abdul Muchith, Haris Hanifah, et al dengan judul "Islamophobia dalam Bias Film Hollywood" (Rif'ati, et al. 2018). Studi ini mengkaji Islamophobia yang ada di dalam 5 film Hollywood (Taken 1, Taken 2, Dracula Untold, Java Heat dan Boys of Abu Ghraib) dengan menggunakan teori Content Analysis. Studi ini menunjukan adanya bias pada film Hollywood dimana Islam tergambar sebagai agama yang penuh kekerasan.

Kedua penelitian terdahulu hanya berfokus pada propaganda Antimuslim namun tidak menemukan atau menjelaskan hubungan antara eksepsionalisme Amerika dan propaganda Anti-islam. Penelitian ini berbeda dari kedua penelitian terkait sebab penelitian ini berfokus untuk membuka pesan tersirat tentang eksepsionalisme Amerika dan hubungannya dengan propaganda Anti-islam pada film 12 Strong. Data primer dari penelitian ini adalah dialog dan gambar film yang memuat eksepsionalisme Amerika dan propaganda Anti-islam. Selain itu, penelitian ini juga menggunakan data sekunder seperti artikel mengenai propaganda Anti-islam sebagai referensi penelitian.

Paradigma strukturalisme digunakan untuk melihat struktur yang dibangun dalam film 12 Strong. Kemudian, teori oposisi binari dilakukan guna memetakan oposisi biner dalam film tersebut sehingga eksespsionalisme Amerika dapat tergambarkan. Selanjutnya, teori propaganda menjadi alat untuk membedah maksut dari oposisi binnari sehingga jenis-jenis propaganda Anti islam dapat terlihat. Dalam proses pengumpulan data, peneliti mengklasifikasikan data berdasarkan beberapa variabel dengan menggunakan teknik observasi dan dokumentasi.

\section{TEORI DAN METODE PENELITIAN}

Untuk membedah film 12 Strong dengan teori oposisi biner, dibutuhkan paradigma strukturalisme sebagai suatu perspektif. Paradigma strukturalisme memiliki pendapat bahwa komponen suatu struktur terdiri dari komponen- 
komponen yang saling memiliki hubungan. Menurut A.J. Greimas, manusia dapat melihat komponen-komponen struktur karena munculnya suatu perbedaan atau pertentangan dari masing-masing komponen atau disebut sebagai oposisi biner.

Misalnya, manusia memahami perempuan sebagai binari dari laki-laki dan hitam sebagai binari dari putih. Dengan kata lain, teori oposisi biner menjelaskan bahwa oposisi biner merupakan suatu tatanan bahasa yang memiliki makna atau nilai yang keberadaannya harus diseimbangkan dengan keberadaan yang lain. A.J. Greimas menyebutkan bahwa struktur dari oposisi biner membentuk bahasa, pengalaman, dan narasi yang digunakan untuk mengartikulasikan pengalaman (Tyson 2006).

Sedangkan teori propaganda digunakan untuk melihat bagaimana film ini melakukan propaganda anti-islam. Harold Lasswell mengatakan bahwa propaganda adalah suatu teknik yang digunakan oleh para pelaku propaganda untuk mempengaruhi perilaku manusia melalui manipulasi kondisi tertentu (Nurudin 2008). Dalam melakukan propagandanya, para pelaku propaganda memiliki teknik dalam menyamarkan tindakannya. Adapun dalam penjelasan Institute for Propaganda Analysis (IPA) (Lee, Lee and IPA 1939) terdapat 7 hal yang menjadi teknik dalam melakukan propaganda.

Pertama, dengan melakukan "Name Calling” artinya penggunaan sebutan atau nama yang menjadi panggilan agar mudah diingat, namun biasanya sebutan tersebut merupakan nama yang memiliki konotasi negatif. Kedua, "Bandwagon" atau ikut serta. Melalui teknik ini, propagandis mengemukakan gagasan bahwa setiap orang melakukan suatu hal, atau semua orang mendukung suatu pihak serta tujuan tertentu sehingga membuat suatu orang/kelompok harus mengikutinya. Ketiga, "Transferring" atau penggunaan simbol, kutipan, atau gambar orang terkenal untuk menyampaikan atau mentransfer suatu pesan propaganda.

Teknik propaganda ke-empat adalah "Card Stacking" atau pemilihan perkara yang dilihat hanya dari satu sisi sudut pandang. Hal ini membuat sisi 
yang lain tidak diperlihatkan, sehingga yang dilihat oleh masyarakat adalah satu sisi yang sengaja dibentuk melalui pemilihan fakta dan data yang mendukungnya. Kelima, "Glittering Generalities" yang serupa dengan pendekatan "Transferring". Dalam teknik ini, propagandis menggunakan beberapa pilihan kata agar masyarakat memiliki pendapat yang positif tentang suatu hal.

Selanjutnya adalah teknik "Plain Folks". Teknik ini biasanya dimanfaatkan oleh seorang politikus untuk menarik dukungan masyarakat, dengan pendekatan untuk meyakinkan masyarakat bahwa hal yang disebarkan itu baik. Teknik ketujuh adalah "Testimonial" dimana teknik ini dilakukan dengan cara mengikutsertakan orang lain untuk memberikan komentar positif tentang suatu gerakan, filosofi, atau kandidat politik (Nduka N. Nwankpa, 2021). Tujuh teknik ini tidak saling terkait sehingga suatu media dapat menerapkan salah satu teknik propaganda untuk mempromosikan suatu nilai atau gagasan kepada kelompok lain.

\section{HASIL DAN PEMBAHASAN}

\section{A. Indoktrinisasi Eksepsionalisme Amerika}

Seiring dengan pertumbuhan teknologi yang juga menunjang aspek perfilman, pertumbuhan jumlah penonton juga turut berkembang. Nilai film sebagai bagian dari hiburan publik ataupun sarana potensial indoktrinasi semakin tergambar. Salah satu indoktrinasi yang bisa penulis temukan dalam film 12 Strong adalah adanya indoktrinasi atau penanaman gagasan, sikap, cara berfikir dan kepercayaan akan adanya eksepsionalisme Amerika. Nilai eksepsionalisme Amerika yang ditanamkan di dalam film ini digambarkan dari segi naratif dan juga dari segi non-naratif. 


\section{Superior dan Inferior}

\begin{tabular}{c|c}
\hline Amerika (Barat) & Afghanistan (Timur) \\
\hline Pempimpin & Bawahan \\
Sky (Langit) & Land (Daratan) \\
Kuat & Lemah \\
Unggul & Biasa \\
Teknologi Maju & Minim Teknologi \\
\hline
\end{tabular}

Dalam 12 Strong penggambaran struktur oposisi biner Amerika merupakan pihak yang superior sedangkan pihak non-Amerika atau pihak Afghanistan atau Timur Tengah merupakan pihak yang inferior. Terlihat dari menit-menit awal film dimulai ketika pasukan Amerika yang dimpimpin oleh Mitch Nelson tiba di pangkalan Uzbekistan. Petinggi militer Amerika di pangkalan Uzbekistan menjelaskan bahwa pasukan Nelson akan bekerjasama dengan pasukan Jendral Dostum.

$\begin{array}{ll}\text { "Kepala Militer } & \text { : Dostum tidak bisa mengalahkan Taliban } \\ & \text { sendirian. Jadi inilah rencananya. Kami akan } \\ & \text { menurunkan Anda ke Afghanistan Utara. Di sana, } \\ & \text { Anda akan bertemu dengan seorang C.I.A. agen } \\ & \text { yang akan membawa Anda ke Dostum." } \\ & (00: 15: 56-00: 16: 05) \\ & \text { "Dostum cannot take out the Taliban by himself. So } \\ & \text { here is the plan. We are gonna drop you into Northern } \\ & \text { Afghanistan. There, you will meet up with a C.I.A. } \\ \text { operative who will take you to Dostum." (00:15:56- } & \text { 00:16:05) }\end{array}$

Dalam percakapan ini terlihat bahwa Dostum adalah kepala pasukan di Afghanistan. Meskipun Dostum mengenal daerah tersebut, Dostum tetap membutuhkan bantuan Amerika Serikat sebagai pemimpin untuk menaklukan Taliban dan mengambil alih kota Mazar-I-Sharif.

Narasi selanjutnya yang menunjukan superioritas Amerika Serikat adalah saat pertemuan pertama antara pasukan Nelson dan pasukan Dostum di daerah bernama Alamo. Penanaman nilai atau paham eksepsionalisme Amerika tergambar jelas ketika Nelson berdebat dengan Dostum. Sebagai penduduk asli yang mengenal daerahnya lebih baik dari pada Nelson, Dostum 
tidak ingin membagikan informasi kepada pihak Amerika karena kepercayaan belum sepenuhnya terbentuk.

$\begin{array}{ll}\text { "Nelson } & : \text { Jenderal, saya kaptennya. Ini tim saya. } \\ & \text { Anda berbicara dengan saya, oke? } \\ \text { Dostum } & : \text { Ini negaraku. } \\ \text { Nelson } & \text { : Saya mengerti itu. } \\ & \text { Tanahnya milikmu, tapi langitnya milik kami" } \\ & (00: 37: 38-00: 37: 48) . \\ \text { "Nelson } & \text { General, I'm the captain. This is my team. } \\ & \text { You speak to me, all right? } \\ \text { Dostum } & : \text { This is my country. } \\ \text { Nelson } & \text { Y Inderstand that. } \\ & \text { You own the land, but we own the sky" } \\ & \text { (00:37:00:37:48). }\end{array}$

Ucapan Nelson menyiratkan adanya perbedaan kelas antara dirinya dan Dostum. Kata "Land" / "Daratan" dan "Sky" / "Langit” adalah bukti Amerika Serikat dalam menanamkan nilai-nilai superioritas dalam film. Hal ini terlihat dari kata Sky atau langit yang memiliki posisi di atas Land. Sebagian besar masyarakat Amerika memiliki pemikiran bahwa langit merupakan sumber kehidupan karena dari sanalah hujan dan angin tersimpan (Aveni 2005).

Saat pasukan Nelson berjalan menuju target pertama lokasi Taliban yang bernama Bescham bersama dengan pasukan Dostum, mereka melewati Desa Behi. Masyarakat desa tersebut menatap pasukan Nelson dengan penuh perhatian.

“Diller : Tidak, dia memamerkan kita. Dia berkata, "Lihat

Orang Amerika. Mereka ada di sini bersamaku."" (00:45:00)

"Diller : No he is showing us off. He is saying, "Look at the Americans. They are here with me."" (00:45:00).

Ucapan Diller seolah menyiratkan bahwa orang Amerika Serikat merupakan orang orang yang kuat dan dibanggakan oleh pihak Non-Amerika. Secara implisit, kalimat Diller juga menyatakan bahwa Dostum saat ini telah kedatangan kekuatan terbaik yaitu pasukan Amerika.

Analisis non-naratif juga mengindikasikan hal yang sama. Pengambilan gambar ketika Nelson menyebut "Langitnya milik kami" / "we own the sky" tidak hanya merujuk ke wajah Nelson tetapi juga memperlihatkan dua orang kulit putih dibelakangnya yang terlihat tersenyum dan melemparkan 
pandangan ke arah orang orang Dostum. Pengambilan gambar juga dilakukan sedikit dari bawah dan seolah membuat wajah Nelson menjadi tampak sedikit lebih tinggi (Gambar 1.). Penggunaan kata "kita" / "we" yang memperlihatkan tiga orang White Anglo-Saxon Protestan (WASP) juga dapat dikategorikan sebagai indoktrinasi eksepsionalisme Amerika.

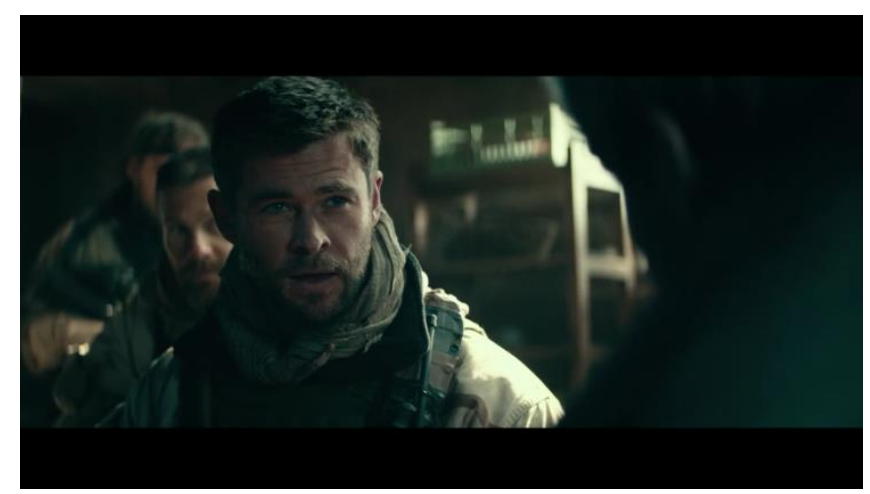

Gambar 1: Nelson dan Dostum terlibat perdebatan mengenai strategi untuk menghadapi anak buah Taliban.

Selanjutnya, penggambaran superioritas Amerika bisa dilihat dari teknik peperangan yang ditampilkan antara Nelson yang mewakili Amerika dan juga Dostum yang mewakili non-Amerika. Seolah berusaha menekan Dostum, Nelson dengan kesal mengatakan bahwa ialah satu satunya jalan keluar yang bisa membantu Dostum mengalahkan Taliban karena kemajuan persenjataan yang Amerika miliki.

"Nelson : Beri saya informasi yang saya butuhkan, dan saya akan memberi penghargaan kepada mereka semua. Jenderal, aku adalah penghubungmu dengan persenjataan terhebat dalam sejarah peradaban" (01:07:38).

"Nelson : Give me the goddamn information I need, and I'll reward every last one of them. General, I'm your link to the greatest weaponry in the history of civilization" (01:07:38).

Penggunaan kata "paling unggul" / "greatest" yang disandingkan dengan kata "peradaban" / "civilization" bisa diartikan sebagai bentuk eksepsionalitas Amerika. The greatest sendiri memiliki atau kekuatan yang bisa dikaitkan dengan pangkat dan kesuperioritasan (Merriam Webster, s.v. "greatest"). Hal ini 
berlawanan dengan penggambaran Dostum yang mewakili orang non-Amerika atau orang Timur Tengah. Dostum dan anak buahnya menggunakan kuda dan persenjataan sederhana saat perang, sementara pihak Amerika tergambar dengan pesawat tempur berisikan rudal dengan kemajuan teknologi koordinat dimana kedua hal ini akan terlihat kontras jika disandingkan.

Superioritas Amerika Serikat kembali ditampilkan saat Taliban berhasil dikalahkan dan Dostum mendapatkan kota Mazar-I-Sharif kembali. Saat itu Nelson mendapat pesan dari petinggi militer Amerika Serikat, dan jawaban ini disiarkan melalui siaran televisi Amerika.

“Nelson : : Pak, izinkan saya menjelaskan kenyataan di lapangan. Saya menasihati seseorang bagaimana menggunakan kavaleri berkuda melawan tank T-27, taktik, dan senapan mesin.... Ke mana pun saya pergi, warga sipil dan tentara lokal selalu memberi tahu saya bahwa mereka senang AS telah datang" (01:20:47-01:21:38)

"Nelson : Sir, let me explain the reality on the ground. I'm advising a man how to employ horse-mounted cavalry against T-27 tanks, tactic, and machine gun .... Everywhere I go to, the civilian and local soldiers are always willing to tell me that they are glad the U.S.A. has come" (01:20:47-01:21:38)

Kalimat ini juga menunjukan bahwa pihak Dostum adalah pihak inferior dengan teknologi yang minim. Hal ini terbukti dari kendaraan perang yang Dostum miliki hanyalah kuda. Dostum dan pasukannya tidak bisa memberikan teknologi dan persenjataan mutakhir pada Nelson dan pasukannya. Hal ini disebabkan teknologi dan persenjataan sudah di kuasai oleh Taliban. Sedangkan, penekanan Nelson mengenai penduduk setempat yang sangat mengangungkan kedatangan Amerika bisa diartikan sebagai bentuk rasa white savior complex. Dalam penelitiannya, (Wanti, 2018) menjelaskan bahwa salah satu elemen dari white savior complex adalah adanya suatu bentuk crossing the lines yang tejadi antar budaya dimana disini, Nelson mewakili Amerika memasuki suatu wilayah asing yang kemudian bertujuan untuk menyelematkan Afghanistan. 


\section{Rasional dan Irasional}

\begin{tabular}{c|c}
\hline Amerika (Barat) & Afghanistan (Timur) \\
\hline Logis & Tidak Logis \\
Berakal & Tidak Berakal \\
Peduli & Egois \\
\hline
\end{tabular}

Oposisi biner selanjutnya yang ditemukan adalah bagaimana Nelson dan pasukannya selalu digambarkan sebagai pribadi yang rasional dan lebih berintelektual dibandingkan dengan non-Amerika. Hal ini terlihat saat Nelson dan Dostum memiliki pandangan yang berbeda tentang kematian. Syahid dan jihad yang merupakan sebuah konsep yang telah terdistorsi oleh kaum islam radikal secara gamblang ditampilkan melalui sisi Taliban dan Dostum. Martyrdom atau kematian syahid menjadi tujuan utama para penganut paham radikal dengan mengatas namakan Islam.

Bom bunuh diri yang ditampilkan dalam awal film dan juga penabrakan pesawat di gedung World Trade Center (WTC) menjadi salah satu bentuk syahid yang dilakukan oleh para Muslim/Islam radikal. Sikap tidak logis juga digambarkan oleh Dostum saat hendak menyerang pertahanan Taliban.

$\begin{array}{ll}\text { "Nelson } & \text { : Kami memiliki perintah untuk diikuti. } \\ \text { Dostum } & \text { : Itulah perbedaan antara Anda dan saya. Anda } \\ & \text { memiliki banyak pria di atas Anda. Di atas saya, hanya } \\ & \text { Tuhan." (00:48:44). } \\ \text { "Nelson } & \text { : We have orders to follow. } \\ \text { Dostum } & \text { : That's the difference between you and me. You have many } \\ & \text { men over you. Over me, only God." (00:48:44). }\end{array}$

Perkataan Dostum ini mengindikasikan bahwa ia dan orang orang Taliban yang merupakan penganut paham yang sama tentang martyrdom. Dimana pola pikir ini merupakan suatu pola pikir yang salah dan tidak bisa diterima. Penggambaran ini sangat kontras jika dibandingkan dengan sikap Nelson yang logis dengan berpikir bahwa menjaga dirinya dan pasukannya tetap hidup adalah cara terbaik dalam memenangkan perang.

Penggambaran pasukan Amerika sebagai pasukan yang berakal tergambar saat Nelson mengambil langkah lebih dekat dengan lokasi pasukan 
Taliban. Hal ini ditempuh Nelson sebab koordinat bom yang diturunkan oleh pesawat Amerika tidak tepat sasaran.

“Nelson : Itu konyol. Saya tidak datang ke sini untuk bermainmain. Tetap di sini, saya akan menelepon kembali koordinat. Saya semakin dekat." (00:53:03)

"Nelson : That was ridiculous. I didn't come here to play around. Stay here, I'll call back coordinates. I'm getting closer." (00:53:03)

Peluncuran bom pertama gagal dilakukan sebab Dostum memerintahkan semua pasukan untuk tetap berada jauh dari target sasaran. Dua pemikiran yang berbeda menitikberatkan pada gambaran Non-Amerika dengan strateginya yang salah dan tidak berakal sehingga Amerika mengubah strategi menjadi lebih rasional.

Di lokasi penyerangan selanjutnya, kejadian yang tidak diinginkan terjadi. Pasukan Dostum tidak menyadari adanya senjata cadangan yang telah disiapkan oleh kelompok Taliban di daerah tersebut. Terkepungnya pasukan Dostum dan kurangnya koordinasi membuat Nelson geram.

“Nelson : : Saya berharap Anda berbagi informasi strategis dengan kami. Kalau tidak, apa yang kita lakukan di sini?" (01:06:58).

"Nelson : : I expect you to share strategic information with us. Otherwise what the fuck are we doing here?" (01:06:58).

Kemarahan Nelson memperlihatkan pemikiran Dostum yang irasional dimana ia tidak memberikan informasi mengenai lokasi penyerangan tersebut. Teguran Nelson kepada Dostum digambarkan dapat membuka pemikiran irasional Dostum karena di malam harinya ia memberikan semua informasi mengenai misi selanjutnya. Permintaan Nelson ini dilakukan sebab dia peduli dan tak ingin pasukannya terluka. Sementara Dostum tidak peduli dan bersikap egois dengan tidak berbagi informasi.

\section{Beradab dan Tidak Beradab}

\begin{tabular}{c|c}
\hline Amerika (Barat) & Afghanistan (Timur) \\
\hline Pemberdayaan & Pembunuhan \\
Bermain & Berperang \\
Membeli & Mencuri \\
Tone warna hangat & Tone warna gelap \\
\hline
\end{tabular}


Eksepsionalisme Amerika juga tampak pada oposisi biner dimana orangorang Timur Tengah digambarkan sebagai sekelompok orang - orang yang tidak beradab atau barbar. Penggambaran ini terlihat sangat kontras dengan penggambaran Amerika yang beradab. Dalam 12 Strong, perbandingan yang paling menonjol mengenai keberadaban antara Amerika dan Timur Tengah adalah dalam segi pendidikan.

Salah satu penggambaran tidak beradabnya Timur Tengah adalah saat kelompok Taliban membunuh seorang guru di hadapan para murid perempuan di depan umum. Hal ini ditujukan untuk menanamkan rasa terror bahwa hal yang sama akan terus terjadi jika anak-anak perempuan berusaha untuk mendapatkan pendidikan. Setelah pembunuhan guru yang dianggap melakukan pelanggaran, dia berpidato dengan lantang di hadapan orang orang mengatakan bahwa Allah tidak menghendaki pendidikan untuk anak perempuan di atas usia delapan tahun.

"Pemimpin Taliban : "Anda semua tahu hukum ilahi-Nya. Tidak ada gadis di atas usia delapan tahun yang boleh terpelajar." (00:43:47).

"Taliban's Leader :You all know His divine law. No girl over the age of eight years old is to be educated." (00:43:47).

Meskipun apa yang dikatakan oleh salah satu pimpinan Taliban tersebut merupakan paham yang tidak bisa di temukan di dalam Al Qur'an, perkataan itu membuat warga setempat tidak berkutik. Ini menggambarkan bagaimana sulitnya masyarakat Timur Tingah terutama perempuan dalam mendapatkan pendidikan.

Ketidakberadaban Timur Tengah juga tercermin pada tokoh anak laki-laki bernama Najeeb yang ditugaskan untuk membantu mengawasi dan memandu tim Nelson selama bertugas di Afghanistan. Ia tidak bisa bersekolah karena harus pergi berperang mewakili keluarganya. Hal ini kontras dengan Maddy, 
Sekar Yolanda Azza, Yusrina Dinar Prihatika - Sinematik Teror: Eksepsionalisme Amerika dan Propaganda Anti-Islam dalam Film 12 Strong

anak perempuan Nelson yang memiliki kehidupan yang sangat layak mulai dari pendidikan, kehangatan keluarga dan juga kehidupan yang terjamin. Kondisi Maddy di Amerika Serikat sangat berbeda dengan Najeeb dan anak anak perempuan Timur Tengah lainnya (Gambar 2a dan 2b).

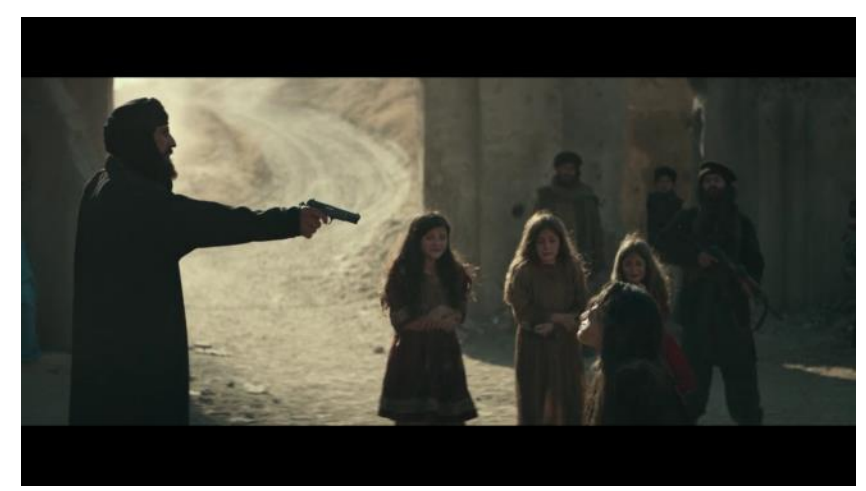

Gambar 2a: Ketua Taliban membunuh guru di hadapan anak perempuan.

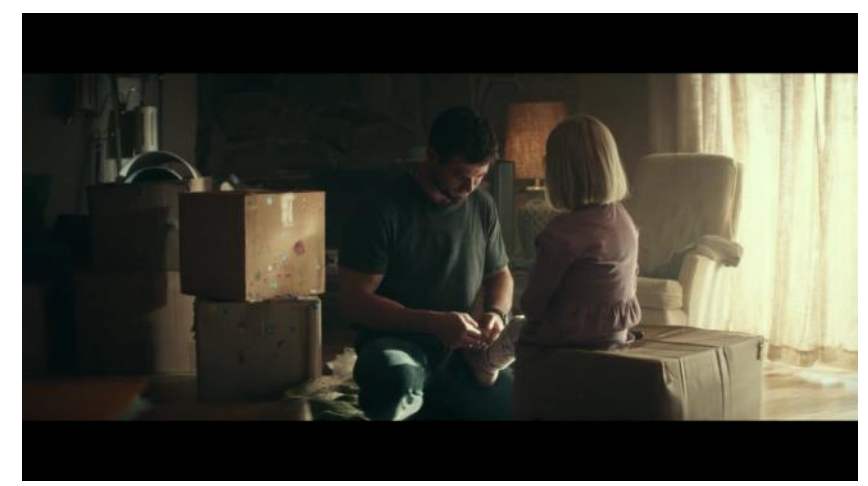

Gambar 2b: Nelson membantu anak perempuannya bersiap berangkat ke sekolah.

Selain masalah pendidikan, situasi di Afghanistan juga di tampilkan dengan gambaran yang tidak beradab. Adegan perang dan saling membunuh merupakan hal yang dianggap wajar. Hal ini jelas berbeda dengan situasi Amerika Serikat yang lebih modern dan beradab dimana anak-anak dapat belajar juga bermain.

"Dostum : karena Anda tinggal di tempat di mana kehidupan terlihat lebih baik daripada kehidupan setelah mati. Itu bukan tempat ini. Di sini, Taliban membunuh semua yang Anda inginkan." (01:07:05).

"Dostum : because you live in a place where life looks better than afterlife. That's not this place. Here, Taliban kills everything you live for." (01:07:05). 
Ucapan Dostum yang menceritakan tentang kondisi Afghanistan kepada Nelson menggambarkan bahwa Amerika merupakan tempat yang lebih beradab dibandingkan daerahnya.

Hal tak beradab lainnya yang ditampilkan dalam film 12 Strong adalah bagaimana orang Timur Tengah beramai-ramai mencuri dan merampas kebutuhan perang dari tentara Amerika yang termasuk stok makanan, seragam perang hingga peralatan berkemah yang kemudian dijual di pasar tradisional. Hal ini terlihat dari percakapan dua pasukan Amerika Serikat yang ingin membeli hasil curian masyarakat lokal.

"Bill Bennett : Saya tidak akan bernegosiasi. Ini sepatu botku. Anda tahu, yang Anda curi dari tempat kami?

Milo : Saya yakin kita bahkan belum menemukan setengah dari barang-barang kita."(00:56:55).

"Bill Bennet : I'm not gonna negotiate. These are my boots. You know, the ones you stole from our drop?

Milo $\quad$ : I bet you we havent even found half our shit."(00:56:55).

Adegan ini menampilkan masyarakat Timur Tengah sebagai orang yang rakus dan tidak beradab karena mencuri dan memungut barang milik orang lain. Sedangkan pasukan Amerika Serikat tergambar sebagai pihak yang beradab karena mereka tetap membeli barang yang telah dijual oleh masyarakat Timur Tengah meskipun barang tersebut milik mereka.

Analisis dari sisi non-naratif juga masih menampilkan hal yang sama, adegan keluarga Amerika ditampilkan dengan tone warna hangat (Gambar 3a) yang seolah menampilkan suasana tenang hangat dan bahagia. Hal ini berbeda dengan tone warna anak-anak di Timur Tengah (Gambar 3b).

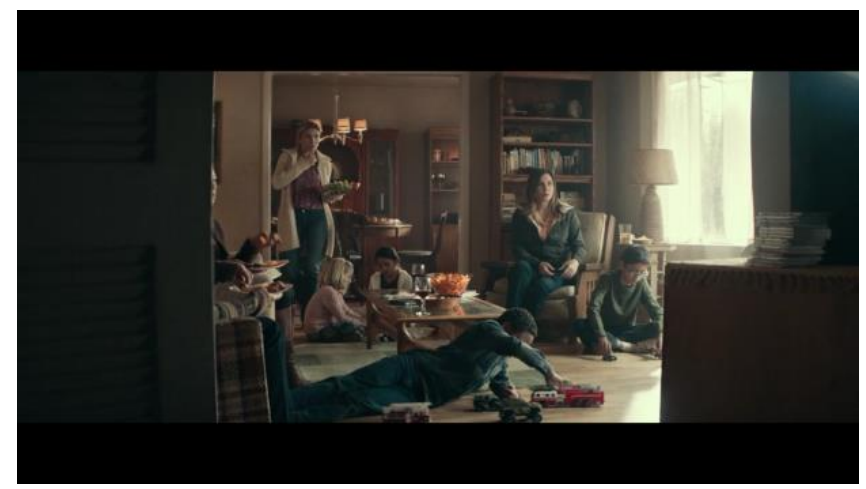


Gambar 3a: Keluarga Nelson yang tengah berkumpul dengan keluarga lain.

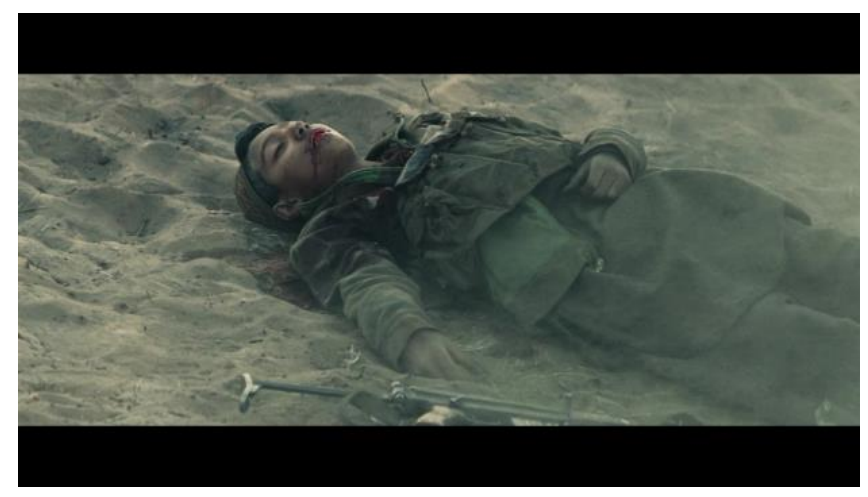

Gambar 3b: Salah satu anak pasukan Taliban yang terbunuh dalam perang.

Ketidakberadaban Timur Tengah sangat bertolak belakang dengan penggambaran keluarga Nelson dan teman-temannya. Mereka digambarkan memiliki keluarga yang harmonis, dengan ekonomi yang cukup baik. Pada saat Nelson sedang dalam penugasan perang di Timur Tengah, istrinya masih sempat mengadakan jamuan perkumpulan dan persiapan Natal. Anak-anak terlihat sibuk dengan mainannya sendiri. Sementara disatu sisi, anak-anak Timur Tengah harus ikut berperang dengan resiko mengorbankan nyawa mereka.

\section{B. Sinematik Teror Dalam 12 Strong}

Bentuk propaganda dalam 12 Strong disebarkan melalui teknik Card Stacking. Pesan yang disampaikan dalam film tersebut adalah perpektif akan Islamophobia atau anti-Islam. Film ini menggambarkan Negara Timur Tengah dan kelompok Muslim sebagai negara dan kelompok yang sangat berbahaya sehingga perlu diwaspadai. Hal ini berbeda dengan penggambaran Amerika Serikat sebagai negara yang heroik, modern, dan beradab. Dampak dari penggambaran yang sepihak ini adalah adanya stereotip dan rasisme yang 
akan dipikul oleh seluruh kelompok Muslim, baik di Amerika Serikat maupun di seluruh penjuru dunia.

Eksepsionalisme yang tercermin melalui opisisi biner merupakan salah satu bentuk agenda Amerika dalam menanamkan ide propaganda mengenai Islam, Timur Tengah dan teroris. Sinematik terror menggunakan teknik “Card Stacking" dimulai sejak awal film, dimana terdapat adegan yang menampilkan serangkaian kejadian terorisme dari beberapa tahun sebelum 9/11. Penggunaan atribut Timur Tengah seperti burqa dan sorban juga ditekankan guna menyebarkan pesan propaganda anti-Islam. Gambar Bin Laden juga di tampilkan lengkap dengan sorbannya (Gambar 4).

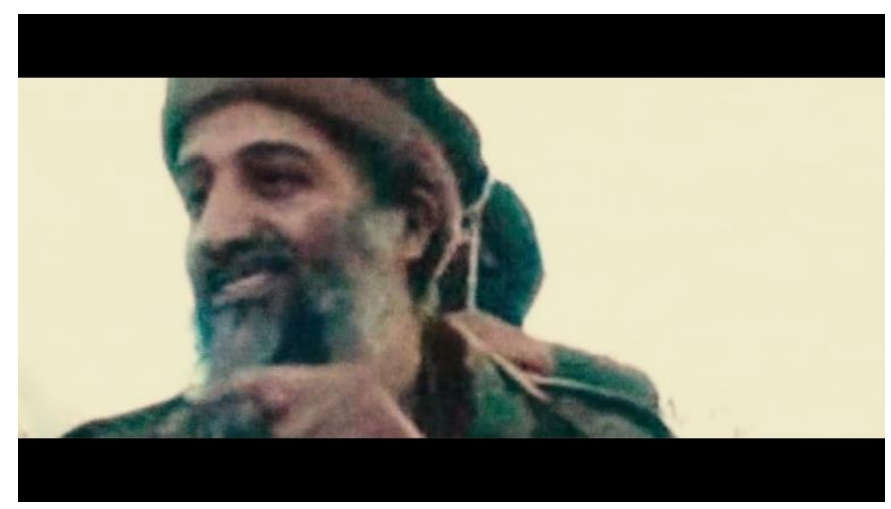

Gambar 4: Pemimpin Al-Qaeda yang membiayai pergerakan Taliban.

Tidak hanya itu, aksesoris Islam berupa sorban kembali muncul dan dilengkapi dengan hadirnya perempuan perempuan lokal yang mengenakan burqa pada saat pasukan Nelson dan Dostum melewati pasar tradisional (Gambar 5) yang kemudian salah satu karakter pasukan Amerika, Sam Diller berkomentar "Aku tidak suka bagaimana mereka memandang kita, Kapten." / "I don't like how they're looking at us, Capt." (44:29). 


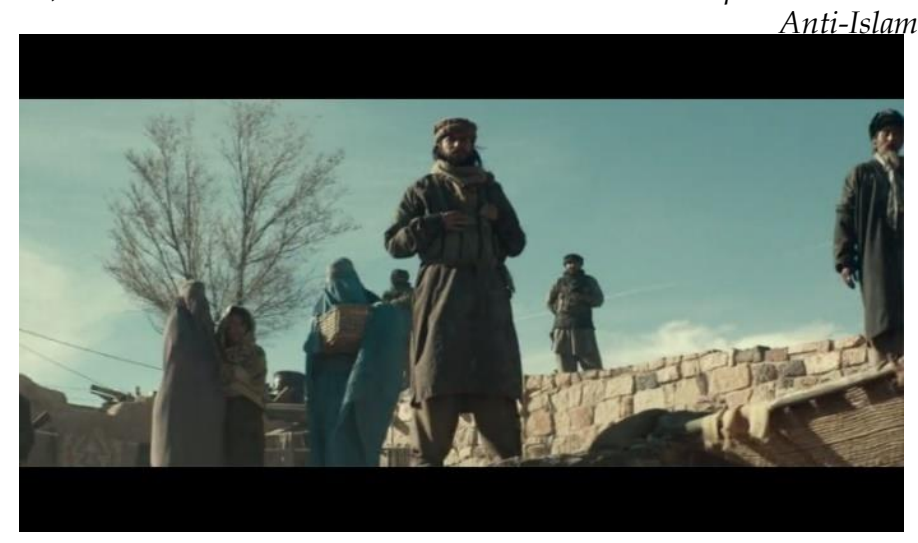

Gambar 5: Masyarakat lokal yang menggunakan sorban dan burqa sedang mengamati pasukan Amerika.

Imam Besar Masjid Al-Azhar, Muhammad Sayyid Thanthawy mengatakan sorban dan burqa merupakan bagian dari kebudayaan Timur Tengah dan tidak ada hubungannya dengan Islam maupun terorisme (Blomfield 2009). Namun melalui film ini, Amerika memberikan rasa teror yang menggambarkan sorban dan burqa sebagai simbol pelaku terorisme. Kekeliruan perspektif akibat propaganda ini dapat membentuk pemikiran masyarakat yang merugikan kelompok Islam. Dengan menimbulkan prasangka negatif melalui media hanya berdasar sorban dan burqa, perlakuan diskriminasi akan merugikan suatu kelompok.

Bentuk propaganda lainnya adalah saat salah satu pasukan Taliban berpura-pura menyerah dan mendekati pasukan Amerika untuk meledakkan bom bunuh diri. Kalimat Takbir berupa Allahu Akbar keluar sebelum bom diledakkan. Ibnu Qayyim (Ghazanfari, Attaran and Zabetipour 2019) mengatakan bahwa Allahu Akbar merupakan kalimat pujian kepada Tuhan kaum Muslim yang berarti Allah Maha Besar. Pasca terjadinya peristiwa 9/11, hampir seluruh dunia melihat ucapan Allahu Akbar sebagi sesuatu kalimat yang menakutkan. Kalimat Takbir yang sesungguhnya memiliki makna dan tujuan yang indah kini sering dikaitkan dengan terorisme, ekstrimisme, kekerasan, kekacauan. 


\section{SIMPULAN}

Bentuk eksepsionalisme Amerika yang muncul dalam film ini dijabarkan dengan bantuan teori binari oposisi. Bentuk variabel eksepsionalisme Amerika yang ditemukan dalam film 12 Strong adalah biner posisi kelas antara superior dan inferior, rasional dan tidak rasional, serta beradab dan tidak beradab.

Teori propaganda juga digunakan untuk menemukan pesan tersirat yang ada di dalam film 12 Strong. Berdasarkan teori propaganda, film ini menggunakan teknik "Card Stacking" dalam menyebarkan pesan propaganda. Pesan propaganda yang tertangkap adalah penggambaran sorban, burqa, dan juga kalimat takbir AllahuAkbar. Propaganda yang terdapat dalam film ini berdampak pada rasa teror bagi kelompok Muslim dan mengakibatkan terjadinya diskriminasi bagi kelompok Muslim.

Paham eksepsionalisme Amerika dan propaganda anti-Muslim pada film 12 Strong memiliki hubungan sebab-akibat. Eksepsionalisme Amerika yang tergambar dalam film dapat membuat masyarakat Amerika berfikir bahwa mereka memiliki status yang lebih baik dibanding warga negara lain. Amerika Serikat memperkuat dirinya dengan menciptakan binari sehingga terciptanya suatu negasi antara dirinya dan negara lain.

Paham eksepsionalisme Amerika kemudian disebarkan melalui berbagai media melalui teknologi sehingga terciptanya propaganda. Teknologi dan informasi yang semakin berkembang akan menjadi bumerang bagi seluruh masyarakat dunia jika tidak dibersamai dengan sikap waspada.

Kejahatan terorisme yang dilakukan oleh pihak manapun wajib untuk dikecam, termasuk kejahatan yang dilakukan jaringan teror Al-Qaeda dan Taliban. Namun, hal yang harus diperhatikan adalah bagaimana dampak serangan balik Amerika Serikat. Amerika Serikat tidak hanya menyerang kelompok terorisme beragama Islam namun juga menyerang keseluruhan kelompok Muslim. Hal ini mengakibatkan kelompok Muslim juga menanggung diskriminasi dan stereotip yang dibentuk Amerika Serikat. 


\section{DAFTAR PUSTAKA}

Aveni, A. F. (2005, 12 21). Ecyclopedia.com. Retrieved 12 5, 2020, from https://www.encyclopedia.com/environment/encyclopedias-almanacstranscripts-and-maps/sky-myths-and-symbolism

Azmi, M. N., Rahman, M. N., Rouyan, N. M., \& Rashid, R. A. (2016). An analysis of stereotype and agenda setting theories in the portrayal of Muslims in The Kingdom. Workshop on High Impact Journal Writing, (pp. 38-54). Malaysia.

Barnett, M. (2016). American exceptionalism and the construction of the war on terror: an analysis of conterrorism policies under Clinton, Bush, and Obama. New York: Maxwell School of Citizenship and Public Affairs, Syracuse University.

Blomfield, A. (2009, October 05). The telegraph. Retrieved January 05, 2021, from https://www.telegraph.co.uk/news/worldnews/africaandindianocean /egypt/6262819/Egypt-purges-niqab-from-schools-and-colleges.html

Diaz, K. G. (2017). Sounds of fear: the sonification of Middle Easterners and Muslims in Hollywood Film, 1950-The Present. California: California State University San Marcos Thesis.

Fuglsig, N. (Director). (2018). 12 Strong [Motion Picture].

Ghazanfari, M., Attaran, A., \& Zabetipour, M. (2019). Contemporary sociopolitical functions of the "Allahu Akbar" ritual speech act in Today's Muslim Communities: A Focus on the Iranian Society. Internationa Journal of Society, Culture E Language, 96.

Institute for Social Policy and Understanding. (2019). American Muslim Poll 2019: Predicting and Preventing Islamophobia. Michigan: ISPU (Institute for Social Policy and Understanding) .

Janz, N. (2010). "And no one will keep that light from shining" Civil religion after September 11 in Speeches of George W. Bush. Berlin: Lit Verlag .

K, A. \&. (2010). A Study of 'Kenry' in Japanese and 'Hak' in Indonesian. Jurnal Humaniora, 22, 22-30.

Langley, R. M. (2011). Ameritocracy: hollywood blockbusters and the universalisation of American values. Birmingham: Department of American and Canadian Studies College of Arts and Law University of Birmingham.

Lee, A. M., Lee, E. B., \& IPA. (1939). The fine art of propaganda. New York: Harcourt Brace and Company.

McFadden, P. (2012). American propaganda and the first world war: megaphone or gangging order? eSharp, 01-32. 
Nduka N. Nwankpa, P. (2021). Media, war and propaganda: a content analysis of U.S. Propaganda in Time and Newsweek coverage of the Iraq war. American Journal of International Relation, 1-16.

Nurudin. (2008). Komunikasi propaganda. Bandung: Rosdakarya.

Reid, A. (2008). Menuju sejarah Sumatra: antara Indonesia dan dunia. Jakarta: Yayasan Obor.

Rif'ati, M. I., Muchith, A., Hanifah, H., Habibullah, W., \& Rarangganis, S. D. (2018). Islamophobia dalam bias film Hollywood. Annual Malang International Peace Conference. Malang.

Tyson, L. (2006). Critical theory today: a user-friendly guide. New York: Routledge.

Wanti, E. (2018). White savior In Melfi's Hidden figures. Semarang: Universitas Diponegoro Thesis.

Zacharek, S. (2008). The New York Times. Retrieved February 12, 2013, from The New York Times:

http:/ / www.nytimes.com/2008/04/27/books/review/Zachareck 